\title{
Erratum to: Directional specificity of postural threat on anticipatory postural adjustments during lateral leg raising
}

\author{
Manon Gendre ${ }^{1,2} \cdot$ Eric Yiou $^{1,2} \cdot$ Thierry Gélat $^{3} \cdot$ Jean-Louis Honeine ${ }^{4}$. \\ Thomas Deroche ${ }^{1,2}$
}

Published online: 20 January 2016

(C) Springer-Verlag Berlin Heidelberg 2016

\section{Erratum to: Exp Brain Res \\ DOI 10.1007/s00221-015-4471-x}

In the original publication of the article, the given and family names of the authors have been swapped. The correct author group is given here.

Manon Gendre, Eric Yiou, Thierry Gélat, Jean-Louis Honeine, Thomas Deroche.

The original article has been updated accordingly.

The online version of the original article can be found under doi: 10.1007/s00221-015-4471-x.

\footnotetext{
Manon Gendre

manongendre@gmail.com

1 Université Paris Sud, Université Paris-Saclay, CIAMS, 91405 Orsay, France

2 CIAMS, Université d'Orléans, 45067 Orléans, France

3 Université Paris Ouest Nanterre, Paris, France

4 Università Degli Studi di Pavia, Pavia, Italy
} 